\title{
Symptoms of hormonal changes in Polish men and women in the second half of life. Andropause and menopause - similarities and differences
}

\begin{abstract}
BACKGROUND
Hormonal changes occur in aging men and women. Considering andropausal changes as similar to menopause, however, is still an open topic. The aim of the research was to assess the occurrence and severity of symptoms associated with hormonal changes in men and women and to find similarities between the male and female climacterium.

PARTICIPANTS AND PROCEDURE

397 individuals (197 men and 200 women) aged 45 to 68 years were examined. The subjects were divided into three groups, with regards to: risk of symptoms, transition period, and andropause/menopause. A sociodemographic survey, the Self-assessment Test, recommended by the pharmaceutical company Organon for the assessment of androgen deficiency in men, and the Women's Health Questionnaire to measure symptoms considered menopausal were used in the research.
\end{abstract}

\section{RESULTS}

The research results showed that menopause-specific symptoms - psychological, vasomotor and sexual - are consid- ered criterial for andropause. However, women experience a greater spectrum of symptoms associated with hormonal changes than men. An analysis of all the symptoms showed that most of them are clearly visible in the oldest group of men and much earlier in women - during the menopausal period.

\section{CONCLUSIONS}

The symptoms observed in men and women in middle and late adulthood are considered to be characteristic of hormonal changes associated with andropause and menopause. However, due to their different scope, dynamics and consequences, the processes in question remain ambiguous.

\section{KEY WORDS}

andropause; menopause; symptoms of hormonal changes

ORgANization - Institute of Psychology, University of Lodz, Lodz, Poland

AUthors' Contributions - A: Study design - B: Data collection - C: Statistical analysis - D: Data interpretation .

E: Manuscript preparation · F: Literature search · G: Funds collection

CORRESPONDING AUthor - Karolina Jarecka, Ph.D., Institute of Psychology, University of Lodz, 10/12 Smugowa Str., 91-433 Lodz, Poland, e-mail: karolina.jarecka@uni.lodz.pl

TO CITE THIS ARTICLE - Jarecka, K. (2021). Symptoms of hormonal changes in Polish men and women in the second half

of life. Andropause and menopause - similarities and differences. Health Psychology Report, 9(3), 252-263.

https://doi.org/10.5114/hpr.2021.102888

RECEIVED 11.10.2020 • REVIEWED 27.10.2020 • ACCEPTED 07.12.2020 • PUBLISHED 20.01.2021 


\section{BACKGROUND}

The health and well-being of men is still at the heart of researchers' concerns. This is justified by the differences in life expectancy between men and women to the detriment of the former. According to the latest data of the Central Statistical Office, the average life expectancy of men in Poland is 73.8 years, while that of women is 81.7 years. The said difference, which indicates excess mortality of men, increases with age. Middle adulthood is already said to be the period associated with the risk of death, but excess mortality is more common in late adulthood. It turns out that $5 \%$ of men and $1.9 \%$ of women die by the age of 45 , while $46.3 \%$ of men and $23.9 \%$ of women do not make it to 75 (Central Statistical Office, 2019).

Life expectancy of men is considered to be affected by various factors - genetic, weaker immune system and greater susceptibility to disease, less concern (compared to women) for own health but also hormonal changes. A drop in hormone levels, including testosterone, increases the risk of cardiovascular diseases (Ho et al., 2016), which prove to be most dangerous for men. They are the main cause of death in Poland. Every second death is caused by cardiovascular diseases and the greatest differences between men and women are observed in this category. Men aged 45-59 years die 3.5 times more often than women due to cardiovascular diseases (Central Statistical Office, 2019).

Research on hormonal changes, in men referred to as andropause, is becoming increasingly important. It is accompanied by the question whether it is appropriate to talk about male menopause or rather changes classified as symptoms should be treated as a potential result of aging and confronting the difficulties of life or specific individual problems.

Undoubtedly, hormonal changes occur in both aging men and women. However, treating andropausal changes as similar to changes accompanying menopause is still an open topic. Discussions mainly concern areas linked with medicine and relate to the assessment of hormone levels. Hormonal changes have a different course and consequences. In women the hormonal function of the ovaries begins to disappear, which is associated with the loss of reproductive capacity, while in men the hormonal function of the testicles is preserved until old age (Mędraś \& Jankowska, 2002; Boul, 2003). Furthermore, changes in the concentration of gonadal hormones in men, concerning the reduction of testosterone concentration, are continuous and are not without individual differences. Additionally, the situation is complicated by the fact that andropause usually develops slowly, mainly between 40 and 55 years of age, and its origins are more complex due to the lack of clear evaluation criteria (Hollander, 2003). It is assumed that andropause occurs after the age of 50 (Bablok \& Mę- draś, 2002). The reduction of testosterone is accelerated between the age of 45 and 50 (Charlton, 2004). Menopause, on the other hand, occurs in a more specific age bracket (usually after the age of 48) and changes are more pronounced than in men (Pertyński \& Stachowiak, 2013). The hormonal changes in women start early - even as early as after the age of 40 , leading to the disappearance of the ovulatory function of the gonads, which significantly affects well-being (Fatusi et al., 2003).

Supporters of the term "andropause" consider the process of change in men as similar to menopause, physiologically conditioned, bringing numerous ailments, negatively affecting the quality of life and requiring treatment. Attention is drawn to similar foundations of diagnosis and recognition of menopause and andropause, i.e. a low concentration of the hormones responsible for the occurrence of symptoms. In women, the levels of female hormones such as progesterone and oestrogens decrease (Stachon, 2013) and the secretion of many male hormones, including androgens, gradually slows down (Rabijewski \& Zgliczyński, 2009). In turn, opponents question the existence of the "male menopause". They claim that andropause is an artificial creation and its symptoms are usually associated with the natural process of aging and do not require medical intervention. In some cases, their occurrence is determined by ill health and/or unhygienic lifestyle, not age (Boul, 2003).

In addition to the commonly accepted names, i.e. male menopause or andropause, there have been more precise terms attempting to link the age-related decline in androgen production and aging symptoms in men. They are late-onset hypogonadism (LOH), which was formally referred to as androgen deficiency in the aging man (ADAM) or partial androgen deficiency in the aging male (PADAM). Both syndromes (PADAM and $\mathrm{LOH}$ ) most often belong to the broadly defined andropausal syndrome (Hisasue \& Horie, 2013; Pines, 2011).

The determination of hypogonadism requires the consideration of key clinical symptoms, such as decreased libido, disorders and loss of morning erection (Renneboog, 2012). Late hypogonadism (LOH), on the other hand, affects middle-aged or older men who have low serum testosterone levels in combination with symptoms of male hypogonadism. The European Male Aging Study (EMAS) defined the following biochemical and clinical criteria for LOH: progressive testosterone ${ }^{1}$ deficiency with age and three sexual symptoms, i.e. erectile dysfunction, reduced sexual thoughts and morning erections. According to EMAS data, it can be almost categorically stated that if a man has no sexual symptoms there is no late hypogonadism (Wu et al., 2010). In epidemiological studies, the relationship between testosterone and sexual desire is statistically significant, but less strict
Andropause and menopause similarities and differences 
due to interactions with other factors that reduce both sexual desire and testosterone levels. Therefore, apart from possible late hypogonadism, other aetiological factors (health, social, economic and psychological factors) and possible sexual disorders should be considered (Lejeune et al., 2013).

Despite extensive research, there are no clear criteria for assessing andropause as in the case of menopause. This is due to inconsistent test results and the symptoms mentioned, considered typical of low testosterone levels, observed not in all men (Huhtaniemi, 2014). This shows that they can be caused not only by hormonal changes, but also by losses suffered by an aging man. It even turns out that diagnosing andropause based on testosterone levels considered "low" is unreliable. Some chronic diseases and medications associated with certain disorders, such as opioids and glucocorticoids, may be partly responsible for lowering testosterone concentration (Hollander, 2003; Huhtaniemi, 2014). Moreover, research shows that only a small group of men experience distinct symptoms of endocrine gonad dysfunction (Pines, 2011).

The aim of the author's present research was to assess the occurrence and intensity of symptoms associated with hormonal changes in men and possible similarities between the male and female climacterium. This required taking into account the dynamics of change of the mentioned symptoms during middle and late adulthood. The age recognized as optimal for andropause and menopause was considered to be a determinant of the expected hormonal changes.

\section{PARTICIPANTS AND PROCEDURE}

\section{STUDY DESIGN AND PROCEDURE}

The conducted study was retrospective and was based on predictive variables. People were selected to take part in the research according to the snowball sampling principle. The recruitment period and data collection lasted 2 years. The research was conducted at the place of residence of the participants, at their workplace, at the University of the Third Century, in district libraries, during reading meetings, in the Łódź Voivodeship in Poland. The study was of individual character and was conducted in the presence of the researcher. The selection of persons for the research was purposeful.

The study required taking into account - considering the purpose of the research - important inclusion variables (age: from 45 to 68 years; gender; having a permanent partner: marriage/cohabitation) and exclusion variables (onerous diseases, living alone).

It is generally considered that people in a permanent relationship are characterised by better mental and physical health than single people (Kamp Dush \& Amato, 2005; Myers, 2007). It has been proved that the lack of social relations leads to premature mortality (Holt-Lunstad et al., 2015).

In turn, the adopted age criterion was justified by previous studies (Bablok \& Mędraś, 2002; Charlton, 2004; Mulligan et al., 2006). In order to obtain more information on the well-being of men who, due to their age (after 65 years of age) finished their professional activity and left the labour market, the study covered people under 68 years of age. This made it possible to unify the conditions of the examined men and women who retire earlier (at the age of 60).

Participants were presented the purpose of the research and information on how it would be carried out. All procedures performed in studies involving human participants were in accordance with the ethical standards of the institutional research committee. All persons consciously agreed to participate in the study.

\section{PARTICIPANTS}

Over 500 people between the ages of 45 and 68 were examined, of whom 397 people (200 women and 197 men) were finally chosen. persons who were single, those with serious chronic diseases and those who did not fill in the questionnaires completely were excluded from the analysis.

The women were divided into three groups according to the experienced menopausal changes (presence and regularity of menstruation). The first group consisted of premenopausal women (menstruating regularly), with the risk of menopausal symptoms (46 subjects aged 45-47); the second group comprised women in the perimenopausal period (menstruating irregularly), also referred to as the transition period (75 subjects aged 48-50); and the third group was made up of postmenopausal women (not menstruating for more than a year) (79 subjects aged 51-68).

The division of men was determined by age ranges which approximately corresponded to the distinguished age groups of women. The lower and upper age limits of men and women remained the same - the differences were between the ranges. The age ranges of the groups of men in the transition period and experiencing andropausal symptoms for more than a year were shifted by two years in relation to the corresponding female groups. This is justified by that fact that the puberty process in boys starts on average about 2 years later, and consequently andropause occurs two years later (after the age of 50) than menopause (after the age of 48). As assumed, the men examined were divided into three groups, with regards to: risk of symptoms (56 subjects aged 45-49), transition period (61 subjects aged 50-52), and the period specific to andropause (80 subjects aged 53-68). 


\section{MEASURES}

Self-assessment Test. A survey, the Self-assessment Test recommended by the pharmaceutical company Organon and the Women's Health Questionnaire were used in the research. The survey was used to verify sociodemographic variables, and the questionnaire methods made it possible to assess the occurrence and intensity of symptoms of hormonal changes (psychological, physical/somatic, vasomotor and sexual).

The questions in the survey concerned: gender, age, marital status, education, and health status. In the women's survey, additional questions were included, aimed at selecting three groups: in the premenopausal period (regularly menstruating), in the perimenopausal period (irregularly menstruating), and in the postmenopausal period (not menstruating for more than a year).

To assess the deficiency of androgens in men, the Self-assessment Test recommended by the pharmaceutical company Organon was used. The test consists of 17 statements describing particular symptoms. They refer to four groups of disorders: physical (weakness, pain, sleep disorders), vasomotor (hot flashes, sweating), psychological (dissatisfaction with life, memory and concentration problems, anxiety), and sexual (erectile dysfunction and loss of morning erections, decrease of sexual desire). The incidence of ailments is assessed on a 4-point scale. The answers are assigned the following points: 0 (never), 1 (sometimes), 2 (often), 3 (always). The following result indicated testosterone deficiency: a minimum of 5 points for sexual and vasomotor disorders or a minimum of 4 points for psychological disorders or a minimum of 8 points for sexual disorders. The higher the score, the more severe the disorders (Bablok \& Mędraś, 2002). The reliability of the test was checked for the results of the present research. Cronbach's $\alpha$ value is in the range from .78 to .82 .

Women's Health Questionnaire. To study menopausal symptoms, the Women's Health Questionnaire (WHQ) was used. It includes 36 statements. The respective groups of statements form scales: depressive mood, somatic symptoms, memory/concentration, vasomotor symptoms, anxiety, sexual behaviour, sleep disorders, menstruation, attractiveness. The index for each scale is obtained by summing up the points awarded to the selected answers and dividing the sum by the number of statements of the scale. The higher the score, the more often the symptoms appear.

When evaluating the symptoms, it is possible to select one of 4 answers. The answers always and sometimes are assigned 1 point, and the answers seldom and never get 0 points. The score must be reversed for some statements. The Women's Health Questionnaire also makes it possible to calculate the total
ZDR-G index. The accuracy of the questionnaire was confirmed by comparison method with the General Health Questionnaire (GHQ). The reliability determined by Cronbach's $\alpha$ value is in the range of .69-.96 (Hunter, 1992). The test reliability, for the results of the present research, measured by the Cronbach's $\alpha$ index, is in the range from .80 to .86 .

\section{STATISTICAL METHODS}

Statistical analyses were selected respectively to the purpose of the study. This choice was also conditioned by objective factors - the size of groups and their number. Using the limit theorems, the assumption of normality of the distribution of examined variables was rejected. This is due to the size of the examined sample (Serfining, 1991; Szymczak, 2008). The statistical analysis of data was based on Pearson's $r$ correlation analysis which allows assessment of the relationship between the studied variables, one-way ANOVA analysis of variance for comparing the means of several groups, and Tukey's HSD test (for post hoc multiple comparisons) (Szymczak, 2008). Statistical calculations were made using the IBM SPSS 24 software with AMOS. The statistical significance level was set at $p<.05$.

\section{RESULTS}

\section{CHARACTERISTICS OF THE STUDY GROUP}

The target population consisted of 397 people, including 197 men (average age 53.56, $S D=9.33$ ) and 200 women (average age 55.91, $S D=8.76$ ), who were assigned to appropriate age groups. All participants lived in Poland, and were of Polish nationality. All participants had secondary or higher education, and were in permanent relationships - marriage or cohabitation. Most of the respondents were married ( $88 \%$ of women and $82.2 \%$ of men). A few people ( $12 \%$ of women and $17.8 \%$ of men) were in cohabitation. Usually it was another relationship (after the marriage was dissolved) and lasted much shorter than the marital one. There was no significant relationship between gender and the form of relationship $\left(\chi^{2}=2.61, p=.070\right)$.

\section{ANDROPAUSAL AND MENOPAUSAL SYMPTOMS - ANALYSIS OF CHANGES IN THE AGE GROUPS OF MEN AND WOMEN}

The symptoms indicating andropause were examined using the Self-assessment Test. Tables 1 and 2 show the results of comparisons of andropausal symptoms in men belonging to three age groups: $45-49$ years
Andropause and menopause similarities and differences 
Table 1

Symptoms of androgen deficiency in men in three age groups

\begin{tabular}{|c|c|c|c|c|c|c|}
\hline \multirow[t]{2}{*}{ Andropausal symptoms } & \multirow[t]{2}{*}{ Age } & \multirow[t]{2}{*}{$N$} & \multirow[t]{2}{*}{$M$} & \multirow[t]{2}{*}{$S D$} & \multicolumn{2}{|c|}{$\begin{array}{c}\text { ANOVA variance } \\
\text { analysis }\end{array}$} \\
\hline & & & & & $F(3,194)$ & $p$ \\
\hline \multirow[t]{3}{*}{ Physical disorders } & $45-49$ & 56 & 3.59 & 1.86 & 15.37 & $<.001$ \\
\hline & $50-52$ & 61 & 4.10 & 1.74 & & \\
\hline & $53-68$ & 80 & 5.36 & 2.13 & & \\
\hline \multirow[t]{3}{*}{ Vasomotor disorders } & $45-49$ & 56 & 2.09 & 1.74 & 11.24 & $<.001$ \\
\hline & $50-52$ & 61 & 2.46 & 1.59 & & \\
\hline & $53-68$ & 80 & 3.46 & 1.91 & & \\
\hline \multirow[t]{3}{*}{ Psychological disorders } & $45-49$ & 56 & 4.27 & 1.88 & 0.24 & .784 \\
\hline & $50-52$ & 61 & 4.28 & 1.96 & & \\
\hline & $53-68$ & 80 & 4.47 & 2.09 & & \\
\hline \multirow[t]{3}{*}{ Sexual disorders } & $45-49$ & 56 & 2.98 & 3.02 & 13.52 & $<.001$ \\
\hline & $50-52$ & 61 & 4.15 & 2.65 & & \\
\hline & $53-68$ & 80 & 5.33 & 2.21 & & \\
\hline \multirow[t]{3}{*}{ Vasomotor + sexual disorders } & $45-49$ & 56 & 5.09 & 4.14 & 15.96 & $<.001$ \\
\hline & $50-52$ & 61 & 6.59 & 3.81 & & \\
\hline & $53-68$ & 80 & 8.71 & 3.41 & & \\
\hline \multirow[t]{3}{*}{ Overall result } & $45-49$ & 56 & 12.93 & 6.38 & 15.35 & $<.001$ \\
\hline & $50-52$ & 61 & 15.03 & 6.20 & & \\
\hline & $53-68$ & 80 & 18.63 & 5.76 & & \\
\hline
\end{tabular}

(risk of symptoms), 50-52 years (transition period), and 53-68 years (andropause).

Men from the oldest group (53-68 years of age) complained about physical, vascular and sexual disorders, which were found to be more severe in comparison to the groups of men aged $45-49(p<.001)$ and 50-52 $(p<.05)$. A similar direction of differences was recorded with respect to the indicator representing the sum of vascular and sexual symptoms $(p<.05)$. The overall result for these symptoms was the highest $(M=8.71)$ in men in the third age group (53-68 years), but was also high in those in the transition period, i.e. aged 50-52 years $(M=6.59)$, and indicated a testosterone deficiency. According to the assumptions of the Self-assessment Test that the result (the sum of vasomotor and sexual symptoms) greater than 5 indicates andropause, the youngest men (45-49 years) should be treated as a risk group for androgen deficiency $(M=5.09)$. Psychological disorders do not differentiate between the examined age groups of men, but assume values indicating (according to the assumptions of the Self-assessment Test) a deficiency of androgens for all of them. Also, the general index of andropausal symptoms was found to be the highest in men aged 53-68 years and significantly differentiated them from younger men $(45-49$ years $)(p<.001)$ as well as from those aged $50-52$ years $(p=.002)$.

It was evaluated in which age groups there was the highest risk of intensification of symptoms associated with hormonal changes in men. Dependencies were present only in the oldest group of men, i.e. from 53 to 68 years old.

Almost all symptoms (except for psychological disorders) intensify in the group of men aged 53-68. The strength of the correlation between the variables under examination is weak or moderate. Significant correlation coefficients were obtained for physical, vasomotor and sexual disorders, the sum of vasomotor and sexual disorders, and the overall result $(p<.05)$.

Age-related tendencies of symptom intensification can be observed in four out of five variables analysed. This leads to a conclusion that $80 \%$ of the symptoms are determined by the aging process of men. A clear increase in the intensity of symptoms with age is observed (Table 1). Considering their 
Table 2

Symptoms of androgen deficiency in men in three age groups - Tukey's HSD test

\begin{tabular}{lrrr}
\hline $\begin{array}{l}\text { Andropausal } \\
\text { symptoms }\end{array}$ & \multicolumn{2}{c}{ Age } & $p$ \\
\hline Physical disorders & $45-49$ & $50-52$ & .333 \\
& & $53-68$ & $<.001$ \\
& $50-52$ & $53-68$ & $<.001$ \\
Vasomotor disorders & $45-49$ & $50-52$ & .496 \\
& & $53-68$ & $<.001$ \\
Sexual disorders & $50-52$ & $53-68$ & $\mathbf{. 0 0 3}$ \\
& $45-49$ & $50-52$ & $\mathbf{. 0 4 3}$ \\
& & $53-68$ & $<.001$ \\
Vasomotor + sexual & $45-49$ & $50-52$ & .080 \\
disorders & & $53-68$ & $<.001$ \\
& $50-52$ & $53-68$ & .023 \\
Overall result & $50-52$ & $53-68$ & .003 \\
& $45-49$ & $50-52$ & .150 \\
& & $53-68$ & $<.001$ \\
& $50-52$ & $53-68$ & $\mathbf{. 0 0 2}$ \\
\hline
\end{tabular}

level, it should be assumed that the critical period related to the occurrence of changes such as physical, vasomotor and sexual disorders, the sum of vasomotor and sexual disorders, is 53-68 years old. For men in the transition period, i.e. 50-52 years, sexual disorders are a noticeable symptom. The men from this group clearly notice more changes in their sexual functioning than men aged 45-49, although fewer than in older men (53-68).

The survey using the Women's Health Questionnaire made it possible to indicate typical symptoms occurring in women during menopause. The results of menopausal symptoms in premenopausal, perimenopausal (menopausal transition) and postmenopausal women were compared (Tables 4 and 5).

Women in the menopausal transition period experience as many as five symptoms (similarly to postmenopausal women) and two symptoms are experienced most intensely. In women in the perimenopausal period, vasomotor symptoms such as hot flashes and sweating as well as those related to menstruation (e.g. breast ailments and abdominal symptoms) are clearly visible. They are particularly strong in comparison with women from the other groups - both the youngest and the oldest $(p<.05)$. Most of the symptoms (depressive mood, somatic disorders, sleep disorders, anxiety, decreased attrac-
Table 3

Andropausal symptoms in men aged 53-68 $(n=80)$ Pearson correlation coefficient values

\begin{tabular}{|c|c|c|}
\hline Symptoms & & $53-68$ years \\
\hline \multirow[t]{2}{*}{ Physical disorders } & $r$ & .38 \\
\hline & $p$ & $<.001$ \\
\hline \multirow[t]{2}{*}{ Vasomotor disorders } & $r$ & .50 \\
\hline & $p$ & $<.001$ \\
\hline \multirow[t]{2}{*}{ Sexual disorders } & $r$ & .26 \\
\hline & $p$ & .019 \\
\hline \multirow{2}{*}{$\begin{array}{l}\text { Vasomotor + sexual } \\
\text { disorders }\end{array}$} & $r$ & .42 \\
\hline & $p$ & $<.001$ \\
\hline \multirow[t]{2}{*}{ Overall result } & $r$ & .43 \\
\hline & $p$ & $<.001$ \\
\hline
\end{tabular}

Andropause and menopause similarities and differences tiveness) remain at an unfavourable level - as early as during the menopausal transition - similar to those observed in postmenopausal women $(p>.05)$. A similar direction of differences concerned the overall result. Menopausal transition is the most difficult period for women.

It was evaluated in which age groups there was the highest risk of intensification of symptoms associated with hormonal changes in women (Table 6). Dependencies were found only for the group of oldest women in the postmenopausal period (aged 51-68 years).

Finally, out of the nine symptoms analysed, three were considered age-dependent and occurred in the oldest women. They accounted for $33.3 \%$ of all the symptoms. The results in Table 6 confirm that disorders related to memory and concentration, as well as sexual and somatic disorders, are most severely experienced by the oldest women (after menopause). The overall result of menopausal symptoms also correlates with the age of women.

\section{COMPARISON OF ANDROPAUSE AND MENOPAUSE}

Comparing andropause to menopause is difficult because they are diagnosed using different methods, which in turn are based on different, both in quantitative and qualitative terms, symptoms. Despite these difficulties, an attempt was made to compare the symptoms of andropause and menopause. It was previously established that the obtained required level of andropause-specific symptoms (psychological and vasomotor, and sexual totals) indicates a deficiency of androgens. Three symptoms specific to men were 
Table 4

Menopausal symptoms in premenopausal, perimenopausal and postmenopausal women

\begin{tabular}{|c|c|c|c|c|c|c|}
\hline \multirow[t]{2}{*}{ Menopausal symptoms } & \multirow[t]{2}{*}{ Group of women } & \multirow[t]{2}{*}{$N$} & \multirow[t]{2}{*}{$M$} & \multirow[t]{2}{*}{$S D$} & \multicolumn{2}{|c|}{$\begin{array}{c}\text { ANOVA variance } \\
\text { analysis }\end{array}$} \\
\hline & & & & & $F(3,197)$ & $p$ \\
\hline \multirow[t]{3}{*}{ Depressive mood } & Premenopause & 46 & 0.16 & 0.20 & 3.30 & .039 \\
\hline & Perimenopause & 75 & 0.23 & 0.24 & & \\
\hline & Postmenopause & 79 & 0.27 & 0.25 & & \\
\hline \multirow[t]{3}{*}{ Somatic symptoms } & Premenopause & 46 & 0.30 & 0.24 & 12.27 & $<.001$ \\
\hline & Perimenopause & 75 & 0.49 & 0.24 & & \\
\hline & Postmenopause & 79 & 0.51 & 0.25 & & \\
\hline \multirow[t]{3}{*}{ Memory and concentration } & Premenopause & 46 & 0.23 & 0.32 & 16.62 & $<.001$ \\
\hline & Perimenopause & 75 & 0.47 & 0.31 & & \\
\hline & Postmenopause & 79 & 0.60 & 0.39 & & \\
\hline \multirow[t]{3}{*}{ Vasomotor symptoms } & Premenopause & 46 & 0.16 & 0.33 & 39.88 & $<.001$ \\
\hline & Perimenopause & 75 & 0.73 & 0.30 & & \\
\hline & Postmenopause & 79 & 0.58 & 0.39 & & \\
\hline \multirow[t]{3}{*}{ Anxiety } & Premenopause & 46 & 0.22 & 0.29 & 4.17 & .017 \\
\hline & Perimenopause & 75 & 0.36 & 0.28 & & \\
\hline & Postmenopause & 79 & 0.36 & 0.28 & & \\
\hline \multirow[t]{3}{*}{ Sexual behaviour } & Premenopause & 46 & 0.26 & 0.34 & 20.26 & $<.001$ \\
\hline & Perimenopause & 75 & 0.39 & 0.36 & & \\
\hline & Postmenopause & 79 & 0.66 & 0.37 & & \\
\hline \multirow[t]{3}{*}{ Sleep disorders } & Premenopause & 46 & 0.26 & 0.27 & 10.60 & $<.001$ \\
\hline & Perimenopause & 75 & 0.49 & 0.30 & & \\
\hline & Postmenopause & 79 & 0.49 & 0.32 & & \\
\hline \multirow[t]{3}{*}{ Menstruation } & Premenopause & 46 & 0.34 & 0.28 & 22.06 & $<.001$ \\
\hline & Perimenopause & 75 & 0.48 & 0.30 & & \\
\hline & Postmenopause & 79 & 0.20 & 0.21 & & \\
\hline \multirow[t]{3}{*}{ Attractiveness } & Premenopause & 46 & 0.27 & 0.38 & 5.56 & .004 \\
\hline & Perimenopause & 75 & 0.48 & 0.36 & & \\
\hline & Postmenopause & 79 & 0.47 & 0.37 & & \\
\hline \multirow[t]{3}{*}{ Overall result } & Premenopause & 46 & 2.21 & 0.60 & 24.54 & $<.001$ \\
\hline & Perimenopause & 75 & 4.13 & 0.47 & & \\
\hline & Postmenopause & 79 & 4.13 & 0.79 & & \\
\hline
\end{tabular}

taken into account for comparison, i.e. psychological (dissatisfaction with life, memory and concentration disorders, anxiety), vasomotor (hot flashes, sweating), and sexual (disorders and loss of morning erections, decrease of sexual desire). An attempt was made to select the menopausal symptoms that would correspond to those of andropause. Three symptoms, i.e. reduced mood (depressive mood), memory and concentration disorders, and anxiety, were classified as psychological. The mean of the sum of the three symptoms was calculated for three groups of examined women: premenopausal $(M=0.21, S D=0.29)$, 
Table 5

Menopausal symptoms in premenopausal, perimenopausal and postmenopausal women - Tukey's HSD test

\begin{tabular}{|c|c|c|c|}
\hline \multirow{2}{*}{$\begin{array}{l}\text { Menopausal symptoms } \\
\text { Depressive mood }\end{array}$} & \multicolumn{2}{|c|}{ Group of women } & \multirow{2}{*}{$\frac{p}{.191}$} \\
\hline & Premenopause & Perimenopause & \\
\hline & & Postmenopause & .030 \\
\hline & Perimenopause & Postmenopause & .629 \\
\hline \multirow[t]{3}{*}{ Somatic symptoms } & Premenopause & Perimenopause & $<.001$ \\
\hline & & Postmenopause & $<.001$ \\
\hline & Perimenopause & Postmenopause & .888 \\
\hline \multirow[t]{3}{*}{ Memory and concentration } & Premenopause & Perimenopause & .001 \\
\hline & & Postmenopause & $<.001$ \\
\hline & Perimenopause & Postmenopause & .047 \\
\hline \multirow[t]{3}{*}{ Vasomotor symptoms } & Premenopause & Perimenopause & $<.001$ \\
\hline & & Postmenopause & $<.001$ \\
\hline & Perimenopause & Postmenopause & .019 \\
\hline \multirow[t]{3}{*}{ Anxiety } & Premenopause & Perimenopause & .023 \\
\hline & & Postmenopause & .031 \\
\hline & Perimenopause & Postmenopause & .985 \\
\hline \multirow[t]{3}{*}{ Sexual behaviour } & Premenopause & Perimenopause & .117 \\
\hline & & Postmenopause & $<.001$ \\
\hline & Perimenopause & Postmenopause & $<.001$ \\
\hline \multirow[t]{3}{*}{ Sleep disorders } & Premenopause & Perimenopause & $<.001$ \\
\hline & & Postmenopause & $<.001$ \\
\hline & Perimenopause & Postmenopause & .999 \\
\hline \multirow[t]{3}{*}{ Menstruation } & Premenopause & Perimenopause & .019 \\
\hline & & Postmenopause & .008 \\
\hline & Perimenopause & Postmenopause & $<.001$ \\
\hline \multirow[t]{3}{*}{ Attractiveness } & Premenopause & Perimenopause & .008 \\
\hline & & Postmenopause & .009 \\
\hline & Perimenopause & Postmenopause & .996 \\
\hline \multirow[t]{3}{*}{ Overall result } & Premenopause & Perimenopause & $<.001$ \\
\hline & & Postmenopause & $<.001$ \\
\hline & Perimenopause & Postmenopause & 1.000 \\
\hline
\end{tabular}

perimenopausal $(M=0.36, S D=0.26)$, and postmenopausal $(M=0.42, S D=0.31)$. It should be noted that in the area of psychological and vasomotor symptoms, the statements assessed by women and men were the most similar. Sexual disorders in women also manifest themselves, similarly to men, in reduced sex drive and interest in sex as well as difficulties in achieving sexual stimulation. Due to the specificity of these disorders, the statements for women were slightly different than those for men.

The results of the comparisons made are presented in Figures 1 and 2.

Psychological symptoms (decreased mood, memory and concentration disorders, anxiety) were found to be stronger in women during and after menopause than in women before menopause $(p<.05)$. We do
Andropause and menopause similarities and differences 
Table 6

Menopausal symptoms in women aged 51 to 68 years $(n=79)-$ Pearson correlation coefficient values

\begin{tabular}{lcc}
\hline Menopausal symptoms & & Age \\
\hline Somatic symptoms & $r$ & .37 \\
& $p$ & .001 \\
Memory & $r$ & .45 \\
and concentration & $p$ & $\mathbf{. 0 0 1}$ \\
Sexual behaviour & $r$ & .47 \\
& $p$ & .001 \\
Overall result & $r$ & .38 \\
& $p$ & .001 \\
\hline
\end{tabular}

not observe that kind of growth in men. Male psychological symptoms (dissatisfaction with life, memory and concentration disorders, anxiety) remain at the same level in all three age groups. Sexual disorders increase with age more distinctly in men $(p<.05)$ than in women: pre- and peri-menopausal women similarly evaluate the experienced sexual symptoms $(p>.05)$ and report significantly fewer of them than post-menopausal women $(p<.05)$. On the other hand, vasomotor disorders are similarly experienced by the youngest men, aged 45-49, and those in the transition period, aged 50-52 $(p>.05)$. These symptoms are most severe in the oldest men, aged 53-68, which makes them significantly different from other groups $(p<.05)$. Similar symptoms in women have a different course. They are most severely experienced by women during menopausal transition, as compared to women before and after menopause $(p<.05)$.

\section{DISCUSSION}

Analyses were carried out concerning changes in symptoms considered as andropausal and those related to menopause in three age groups of men and women. It was found that age is the variable responsible for the intensification of the symptoms associated with hormonal changes. Correlations between age and some of the symptoms proved to be significant in the third group, i.e. the oldest men and the oldest women, which shows that the observed changes are apparently related to middle and late adulthood (from 51/53 to 68 years). At the same time, most (80\%) of the symptoms considered to be andropausal increase with age, which concerns only $33.3 \%$ of menopausal symptoms.

The adopted quantitative criterion, indicating deficiency of testosterone - of one of the three symp-
Figure 1

Psychological, sexual, vasomotor symptoms in men for three age groups: 45-49 years (M1), 50-52 years (M2), 53-68 years (M3)

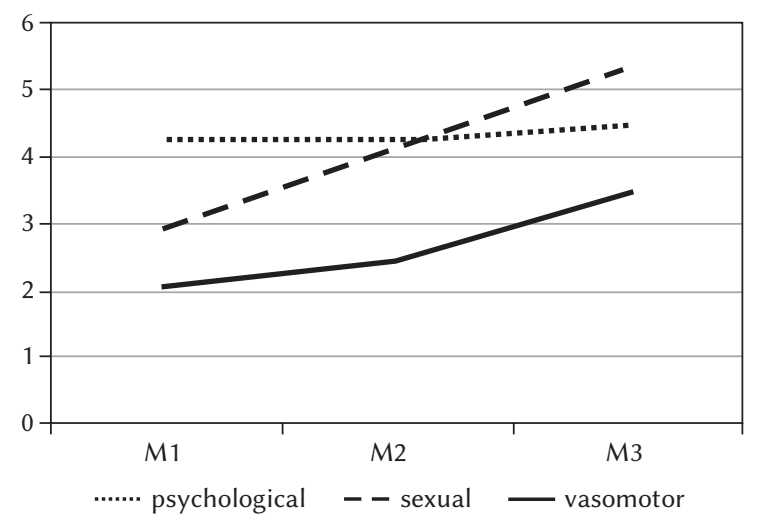

\section{Figure 2}

Psychological, sexual, vasomotor symptoms in women for three age groups: 45-47 years ( $F 1), 48-50$ years ( $F 2)$, 51-68 years $(F 3)$

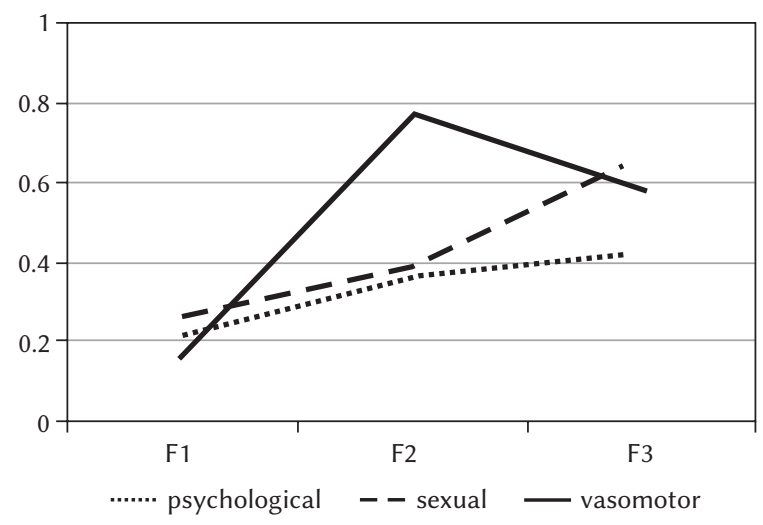

toms: psychological or sexual, or vasomotor and sexual totals (Bablok \& Mędraś, 2002) - was verified positively. All the examined men experienced the expected level of psychological symptoms, but also the expected level of vasomotor and sexual totals, indicating testosterone deficiency. Vasomotor and sexual symptoms intensify with age. Clear growth trends were observed in the men aged 50-52, while the older ones, aged 53-68, reached high rates $(p<.05)$. Other andropausal symptoms (apart from the psychological ones) also increase with age. Research studies confirm that the intensification of symptoms with age in men is consistent with the dependence of the changes on the aging process, during which the amount of androgens, i.e. testosterone, dehydroepiandrosterone and other hormones, gradually decreases, which occurs after 50 years of age (Mędraś \& Jankowska, 2002; 
Bablok \& Mędraś, 2002; Tan, 2001). Testosterone administration, however, does not delay the changes linked with the aging process (Handelsman, 2013).

Further analyses regarding the comparison of andropausal and menopausal changes made it possible to establish a critical period for the intensification of symptoms in men and women. The highest level of symptoms was observed in the oldest men, aged 53-68 years, while for women it was the period of menopausal transition - also defined as perimenopausal and referring to the age range of 48-50 years. Women in this period of life similarly experience most of the symptoms as those after menopause, but also complain the most (compared to the younger and even the oldest group) about vasomotor disorders and symptoms associated with menstruation (breast and abdominal disorders). Since most researchers assume the age of 49 to 52.5 years as typical for the occurrence of the last menstruation in women from different countries (Bielawska-Batorowicz, 2016), menopause should be treated as a process inscribed in women's developmental changes and expected in a specific period of life, similarly to those related to puberty.

Is it even possible to compare andropause to menopause? The above presented attempt to refer key andropausal symptoms (psychological, sexual and vasomotor) to selected menopausal symptoms (psychological, sexual and vasomotor) did not bring the expected results. The dynamics of andropausal symptoms are different from menopausal ones. In men, in all age groups, the psychological symptoms remain at the same criterial level for andropause. In women, on the other hand, the psychological symptoms increase with age. It should be assumed that they may be caused by hormonal changes associated with the loss of menstruation, which is conducive to ailments, but also to women's fears of aging. Augoulea et al. (2019) report that although menopause as such is not correlated with specific psychiatric disorders, data suggest that perimenopausal women are more particularly at risk of developing mood and sleep disorders, neuroticism, anxiety, cognitive decline and stress.

Psychological symptoms need not be identified only with hormonal changes. Their intensity may cause stress, difficulties or unexpected changes in the lives of men and women. Studies confirm that not all psychological symptoms in men are associated with low testosterone levels (Morales et al., 2010).

Sexual disorders are considered diagnostic for andropause in men. The present author's research showed that they increase with age in men but also in women. A drop in testosterone levels is responsible for a decrease in sexual desire in men. The relationship between the increasing number of sexual symptoms and decreasing testosterone levels is confirmed (Heidari et al., 2015; Huhtaniemi, 2014; Renneboog, 2012; Wu et al., 2010). The analyses carried out revealed that sexual symptoms occur in men as early as during the transition period, i.e. at the age of 50-52 years. However, the oldest men aged 53-68 experience them most intensely. According to the conducted studies, sexual problems (related to desire, erection) are assumed to be a typical symptom in men in middle and especially late adulthood (Lejeune et al., 2013).

Vasomotor disorders also increase with age. They were found to be most severe for the oldest men, i.e. aged 53-68, and for the women in the period of menopausal transition, i.e. aged 48-50. This is due to biological, endocrine and even clinical changes in women taking place at the age of 48-50 years (BielawskaBatorowicz, 2016).

Medical research indicates that hormonal changes in men are caused by the aging process (Hisasue \& Horie, 2013; Pines, 2011; Wu et al., 2010), which is not so obvious in women. It was found that there are no similarities between aging and changes in the function of the testicles and ovaries. The function of testicles decreases gradually with age, whereas the ovaries undergo functional involution faster during menopause (Huhtaniemi, 2014). This may explain the earlier appearance of symptoms in women and their intensification during the menopausal period.

The psychological, vasomotor and sexual symptoms observed in women are also found in men. They are considered to be characteristic of the hormonal changes associated with menopause and andropause. However, due to their different dynamics and consequences, the processes in question remain ambiguous. The consequences of menopause involve a broader spectrum of symptoms, including the more distant symptoms associated with the genitourinary syndrome of menopause (GSM).

It has been confirmed that the symptoms of menopause are associated with significant social costs. These costs arise from the need to reduce the symptoms (hormone replacement therapy, psychotherapy, acupressure, herbal compounds, acupuncture, massage, yoga, lifestyle changes such as sports and diet), as well as to treat the long-term consequences of a deficiency in sex hormones. Additional costs include follow-up visits, laboratory tests, adverse event management and loss of productivity at work (Augoulea et al., 2019). However, attention is drawn to the fact that the methods of treating hormonal changes proposed to women are not equally effective and safe for everyone, and the decision to use them is difficult and depends on many factors (the amount of information about menopause, their type and source, mental state related to symptoms) (Bahri et al., 2019).

Although menopause results in a greater number of more severe changes in women's lives, specific symptoms in men should not be treated as natural and thus ignored. However, this is what often happens because a large proportion of men deny the presence of changes, especially in terms of the sexual behaviour. Women do not hesitate to report them;
Andropause and menopause similarities and differences 
therefore much more attention is paid to menopause than to andropause (Fatusi et al., 2003). It turns out that the sexual satisfaction of people undergoing hormonal changes can be positively influenced by interventions aimed at developing the ability to regulate emotions. Women in the menopausal period with competences in this area show greater self-awareness, empathy, and ability to assertively express their own needs, and they better overcome the feeling of shame, which allows them to achieve greater sexual satisfaction (Ansari et al., 2019).

The consequences of hormonal changes in men are also related to the costs they incur in middle and late adulthood; hence the planned interventions and social support should also be directed towards this group of people.

\section{CONCLUSIONS}

The symptoms observed in men and women in middle and late adulthood are considered to be characteristic of hormonal changes associated with andropause and menopause. However, due to their different scope, dynamics and consequences, the processes in question remain ambiguous. Despite these differences, men also require attention, support and professional medical and psychological help.

\section{LIMITATIONS}

The present study is not without limitations because it did not include, apart from age, other variables that may modify the experience of symptoms in the examined subjects. For the assessment of changes taking place in aging men it is important to take into account not only their age but also the possible risk factors of these changes, i.e. lifestyle, diet, physical activity, addictions, etc. Furthermore, comparing andropause to menopause allows one to draw only very cautious conclusions, since their diagnosis is based on different methods, which in turn include different quantitative and qualitative symptoms.

\section{ENDNOTE}

1 Studies indicate that testosterone production in the testicles in aging men decreases by $1-2 \%$ per year after the age of 40 (Pines, 2011).

\section{References}

Ansari, N., Vakilian, K., \& Rezveh, F. M. (2019). Sexual health during menopause - counselling with an approach to emotional regulation on sexual satis- faction. Family Medicine \& Primary Care Review, 21, 318-323. https://doi.org/10.5114/fmpcr.2019.90159.

Augoulea, A., Moros, M., Lykeridou, A., Kaparos, G., Lyberi, R., \& Panoulis, K. (2019). Psychosomatic and vasomotor symptom changes during transition to menopause. Menopause Review, 18, 110-115. https://doi.org/10.5114/pm.2019.86835.

Bablok, L., \& Mędraś, M. (2002). Diagnostyka andropauzy jako częściowej niedomogi androgennej [Diagnosis of andropause as a partial androgenic deficiency]. In M. Mędraś \& L. Bablok (Eds.), Andropause (pp. 42-49). PZWL.

Bahri, N., Sajjadi, M., \& Sadeghmoghadam, L. (2019). The relationship between management strategies for menopausal symptoms and women's decision making styles during menopausal transition. Menopause Review, 18, 174-179. https://doi.org/10.5114/ pm.2019. 90378

Bielawska-Batorowicz, E. (2016). Psychologiczne aspekty menopauzy [Psychological aspects of menopause]. PWN.

Boul, L. A. (2003). Men's health and middle age. Sexualities, Evolution \& Gender, 5, 5-22.

Central Statistical Office (2019). Life expectancy in 2018. Statistical Publishing House.

Charlton, R. (2004). Ageing male syndrome, andropause, androgen decline or mid-life crisis? The Journal of Men's Health and Gender, 1, 55-59. https://doi.org/10.1016/j.jmhg.2004.03.014

Fatusi, A. O., Ijadunola, K. T., Ojofeitimi, E. O., Adeyemi M. O., Omideyi, A. K., Akinyemi, A., \& Adewuyi, A. A. (2003). Assessment of andropause awareness and erectile dysfunction among married men in Ile-Ife, Nigeria. The Aging Male, 6, 79-85.

Handelsman, D. J. (2013). Global trends in testosterone prescribing, 2000-2011: Expanding the spectrum of prescription drug misuse. The Medical Journal of Australia, 199, 548-551. https:// doi.org/10.5694/mja13.10111

Heidari, R., Sajadi, H., Pourmand, A., \& Pourmand, G. (2015). Can testosterone level be a good predictor of late-onset hypogonadism? Andrologia, 47, 433-437. https://doi.org/10.1111/and.12285

Hisasue, S., \& Horie, S. (2013). Role of androgen in the elderly. What is LOH syndrome? Clinical Calcium, 23, 1101-1117. https://doi.org/130811011107

Ho, C. H., Wu, C. C., Chen, K. C., Jaw, F. S., Yu, H. J., \& Liu, S. P. (2016). Erectile dysfunction, loss of libido and low sexual frequency increase the risk of cardiovascular disease in men with low testosterone. The Aging Male, 19, 96-101. https:// doi.org/10.3109/13685538.2015.1129400

Hollander, E. (2003). Male menopause: an unexplored area of men's health. Pediatric Annals, 33, 497-500. https://doi.org/10.3928/0048-5713-20030801-06

Holt-Lunstad, J., Smith, T. B., Baker, M., Harris, T., \& Stephenson, D. (2015). Loneliness and social isolation as risk factors for mortality: a meta-analytic 
review. Perspectives on Psychological Science, 10, 227-237. https://doi.org/10.1177/1745691614568352

Huhtaniemi, I. (2014). Late-onset hypogonadism: Current concepts and controversies of pathogenesis, diagnosis and treatment. Asian Journal of Andrology, 16, 192-202. https://doi.org/10.4103/1008682X.122336

Hunter, M. (1992). The woman's health questionnaire: a measure of mind-aged woman's perceptions of their emotional and psychical health. Psychology and Health, 7, 45-54. https://doi.org/ 10.1080/08870449208404294

Kamp Dush, C. M., \& Amato, P. R. (2005). Consequences of relationship status and quality for subjective well-being. Journal of Social and Personal Relationships, 22, 607-627. https://doi.org/ 10.1177/0265407505056438

Lejeune, H., Huyghe, É., \& Droupy, S. (2013). Hypoactive sexual desire and testosterone deficiency in men. Progres en Urologie, 23, 621-628. https:// doi.org/10.1016/j.purol.2013.01.019

Mędraś, M., \& Jankowska, E. (2002). Testosteron a andropauza i proces starzenia się mężczyzn [Testosterone and andropause and the aging process of men]. In M. Mędraś \& L. Bablok (Eds.), Andropause (pp. 16-19). PZWL.

Morales, A., Bella, A. J., Chun, S., Lee, J., Assimakopoulos, P., Bebb, R., Gottesman, I., Alarie, P., Dugré, H., \& Elliott, S. (2010). A practical guide to diagnosis, management and treatment of testosterone deficiency for Canadian physicians. $\mathrm{Ca}$ nadian Urological Association Journal, 4, 269-275. https://doi.org/10.5489/cuaj.880

Mulligan, T., Frick, M. F., Zuraw, Q. C., Stemhagen, A., \& McWhirter, C. (2006). Prevalence of hypogonadism in males aged at 45 years: the HIM study. International Journal of Clinical Practice, 60, 762-769. https://doi.org/10.1111/j.1742-1241.2006.00992.x

Myers, D. G. (2007). Relationships with people and a good life. Seeking balance between the interests of the individual and the community in social policy. In P. A. Linley \& S. Joseph (Eds.), Positive psychology (pp. 389-411). PWN.

Pertyński, T., \& Stachowiak, G. (2013). Mastalgia: a serious problem in premenopausal women. Menopause Review, 1, 29-33. https://doi.org/10.5114/ pm.2013.33418

Pines, A. (2011). Male menopause: Is it a real clinical syndrome? Climacteric, 14, 15-17. https://doi.org/ 10.3109/13697137.2010.507442

Rabijewski, A., \& Zgliczyński, W. (2009). Etiopatogeneza, rozpoznawanie i leczenie hipogonadyzmu u mężczyzn [Etiopathogenesis, diagnosis and treatment of hypogonadism in men]. Endokrynologia Polska, 60, 222-233.

Renneboog, B. (2012). Andropause and testosterone deficiency: How to treat in 2012? Revue Médicale de Bruxelles, 33, 443-449.
Serfining, R. J. (1991). Twierdzenia graniczne statystyki matematycznej [Limit theorems of mathematical statistics]. PWN

Stachoń, A. J. (2013). Ocena odczuwania wybranych objawów w zależności od fazy klimakterium i charakteru menopauzy [Feeling of the selected climacteric symptoms depending on the climacteric phase and type of menopause]. Menopause Review, 4, 315-320. https://doi.org/10.5114/pm.2013.37847

Szymczak, W. (2008). Podstawy statystyki dla psychologów [Fundamentals of statistics for psychologists]. Difin.

Tan, R. S. (2001). Memory loss as a reported symptom of andropause. Archives of Andrology 47, 185-189. https://doi.org/10.1080/014850101753145889

Wu, F. C., Tajar, A., Beynon, J. M., Pye, S. R., Silman, A. J., Finn, J. D., O’Neill, T. W., Bartfai, G., Casanueva, F. F., Forti, G., Giwercman, A., Han, T. S., Kula, K., Lean, M. E., Pendleton, N., Punab, M., Boonen, S., Vanderschueren, D., Labrie, F., Huhtaniemi, I. T., ... EMAS Group (2010). Identification of late-onset hypogonadism in middle-aged and elderly men. The New England Journal of Medicine, 363, 123-135. https://doi.org/10.1056/NEJM oa0911101
Andropause and menopause similarities and differences 